\title{
2 High-content analysis of $\alpha$-synuclein aggregation and cell death in a cellular model of Parkinson's disease
}

\author{
Q1 Francesca Macchi ${ }^{\mathrm{a}}$, Angélique Deleersnijder ${ }^{\mathrm{a}}$, Chris Van den Haute ${ }^{\mathrm{a}, \mathrm{d}}$, Sebastian Munck ${ }^{\mathrm{b}}$, \\ Hans Pottel $^{\mathrm{c}}$, Annelies Michiels ${ }^{\mathrm{a}, \mathrm{d}}$, Zeger Debyser ${ }^{\mathrm{e}}$, Melanie Gerard ${ }^{\mathrm{a}, \mathrm{f}}$, \\ Veerle Baekelandt ${ }^{a}$,* \\ ${ }^{a}$ KU Leuven, Laboratory for Neurobiology and Gene Therapy, Kapucijnenvoer 33, Leuven B-3000, Flanders, Belgium \\ ${ }^{\mathrm{b}}$ KU Leuven, Department of Human Genetics, Flanders Interuniversity Institute of Biotechnology, Kapucijnenvoer 33, Leuven B-3000, Flanders, Belgium \\ ${ }^{\mathrm{c}}$ KU Leuven Campus Kulak Kortrijk, Public Health and Primary Care, Interdisciplinary Research Facility Life Sciences, Etienne Sabbelaan 53, Kortrijk B-8500, \\ Flanders, Belgium \\ d Leuven Viral Vector Core, KU Leuven, Leuven B-3000, Flanders, Belgium \\ e Laboratory for Molecular Virology and Gene Therapy, Department of Pharmaceutical and Pharmacological Sciences, KU Leuven, Leuven B-3000, Flanders, \\ Belgium \\ ${ }^{\mathrm{f}}$ KU Leuven campus Kulak Kortrijk, Laboratory of Biochemistry, Interdisciplinary Research Facility Life Sciences, Etienne Sabbelaan 53, Kortrijk B-8500, \\ Flanders, Belgium
}

\section{H I G H L I G H T S}

- We describe an optimized high-content assay to simultaneously measure oxidative stress-induced $\alpha$-synuclein aggregation and cell death in human neuronal cell lines.

- The presented method allows the quantification of both $\alpha$-synuclein inclusion formation and apoptosis in an automated, objective and reproducible manner.

- The high-content assay can contribute to the identification of compounds and genes that might alter $\alpha$-synuclein aggregation and toxicity.

\section{A B S T R A C T}

Background: Alpha-synuclein ( $\alpha$-SYN) aggregates represent a key feature of Parkinson's disease, but the exact relationship between $\alpha$-SYN aggregation and neurodegeneration remains incompletely understood. Therefore, the availability of a cellular assay that allows medium-throughput analysis of $\alpha$-SYN-linked pathology will be of great value for studying the aggregation process and for advancing $\alpha$-SYN-based therapies.

New method: Here we describe a high-content neuronal cell assay that simultaneously measures oxidative stress-induced $\alpha$-SYN aggregation and apoptosis.

Results: We optimized an automated and reproducible assay to quantify both $\alpha$-SYN aggregation and cell death in human SH-SY5Y neuroblastoma cells.

Comparison with existing methods: Quantification of $\alpha$-SYN aggregates in cells has typically relied on manual imaging and counting or cell-free assays, which are time consuming and do not allow a concurrent analysis of cell viability. Our high-content analysis method for quantification of $\alpha$-SYN aggregation allows simultaneous measurements of multiple cell parameters at a single-cell level in a fast, objective and automated manner.

Conclusions: The presented analysis approach offers a rapid, objective and multiparametric approach for the screening of compounds and genes that might alter $\alpha$-SYN aggregation and/or toxicity. 


\section{Q3 1. Introduction}

Q4

Parkinson's disease (PD) is a progressive, neurodegenerative disorder characterized by a loss of dopaminergic neurons in the substantia nigra pars compacta. The protein alpha-synuclein ( $\alpha$ SYN) is considered a key player in synucleinopathies, including PD (Deleersnijder et al., 2013). First, aggregated $\alpha$-SYN is a major constituent of Lewy Bodies, i.e. eosinophilic cytoplasmic inclusions that are a pathological hallmark of PD (Spillantini et al., 1997). Second, missense mutations in the $\alpha$-SYN gene (A53T, A30P, E46K, G51D and H50Q) (Appel-Cresswell et al., 2013; Kruger et al., 1998; Lesage et al., 2013; Polymeropoulos et al., 1997; Zarranz et al., 2004) and locus duplication (Chartier-Harlin et al., 2004; Ibanez et al., 2004) or triplication (Singleton et al., 2003) of the wild type (WT) gene were identified as cause of autosomal-dominant monogenetic PD. Finally, overexpression of WT and mutant forms of $\alpha$-SYN in C. elegans, Drosophila, mice, rats and non-human primates leads to neuronal inclusions and/or behavioral symptoms very similar to those observed in PD patients. (Eslamboli et al., 2007; Feany and Bender, 2000; Kirik et al., 2003, 2002; Lakso et al., 2003; Lauwers et al., 2003; Oliveras-Salva et al., 2013; Van der Perren et al., 2014).

Although research on PD has accelerated in the last decade due to increased insight in the pathogenic mechanisms (Gasser, 2009; Lubbe and Morris, 2014; Mizuno et al., 2008; Olanow and Brundin, 2013), there is still a lack of efficient and robust cell culture models. Such assays could speed up the discovery of new candidate inhibitors of PD pathology and in particular of $\alpha$-SYN aggregation.We developed an oxidative stress-induced cellular model of $\alpha$-SYN aggregation in human SH-SY5Y neuroblastoma cells, followed by high-content image-based analysis to simultaneously quantify $\alpha$-SYN aggregate formation and cell death (Aelvoet et al., 2014; Deleersnijder et al., 2011; Gerard et al., 2010; Oliveras-Salvá et al., 2014; Van der Veken et al., 2012). High-content analysis (HCA) is the process of extracting complex information from images of cells and tissues using a combination of automated microscopy and automated image analysis (Denner et al., 2008; Dragunow, 2008; Rausch, 2005). HCA has already been successfully applied to determine several aspects of the brain's complexity, such as neurite outgrowth (Radio, 2012; Vallotton et al., 2007; Wang et al., 2010), neurogenesis (Blackmore et al., 2010), cell count (Narayan et al., 2007), inclusion formation (Boyd et al., 2014; Scotter et al., 2008; Teboul et al., 2007), apoptosis (Dragunow et al., 2006; Fennell et al., 2006), cell migration (Schmandke et al., 2013) and signal transduction (Grimsey et al., 2008). To our knowledge, this technology has not been used yet to study $\alpha$-SYN aggregation, while it has several advantages over manual methods of $\alpha$-SYN aggregate analysis. Most cellular studies thus far have been based on estimating the intensity of Thioflavin $\mathrm{S}$ (Thio S) staining in cells or on manual counting of $\alpha$-SYN inclusion formation, which are both slow, subjective and laborious methods. Moreover, manual methods do not allow to discriminate between changes in aggregate size or density and changes in aggregate number. Furthermore, although biochemical and biophysical techniques (e.g. gel filtration, low speed or analytical centrifugation, transmission electron microscopy, structural stability, protease resistance, turbidity, circular dichroism and immunological investigations) can provide useful information on the size and the nature of the $\alpha$-SYN aggregates, they lack cellular resolution and/or concurrent analysis of cell health or simply do not allow for bigger throughput (Harper and Lansbury, 1997; Lundvig et al., 2005). Additionally, routine application of most of the aforementioned techniques in largescale assays for therapeutically relevant interactions or promising drug therapies is not feasible. Our HCA method for quantifying $\alpha-$ SYN aggregation circumvents the caveats listed above as it allows simultaneous measurements of multiple cell characteristics at a 05 single-cell level in a fast, objective and automated manner. The presented analysis platform offers a rapid, objective and multiparametric approach for the validation of compounds and genes that might alter $\alpha$-SYN aggregation as well as the concurrent measurement of changes in cell viability. This assay allows identification of both inhibitors and stimulators of $\alpha$-SYN aggregation and can also be used to study $\alpha$-SYN aggregation itself.

\section{Materials and methods}

\subsection{Cell culture}

Human SH-SY5Y neuroblastoma cells were grown in Dulbecco's modified Eagle's medium (DMEM) (Gibco-BRL, Life Technologies, Cat No. 31966047), $50 \mathrm{mg} / \mathrm{ml}$ gentamycin (Gibco-BRL, Life Technologies, Cat No. 15750045) and $1 \%$ non essential amino acids (Gibco-BRL, Life Technologies, Cat No. 11140068) (referred to herein as DMEM-complete) at $37^{\circ} \mathrm{C}$ and $5 \% \mathrm{CO}_{2}$ in a humidified atmosphere.

\subsection{Antibodies and other reagents}

DAPI (4',6-diamidino-2-phenylindole, Cat No. D9592), propidium iodide (PI, Cat No. P4170), staurosporine (Cat No. S6942) and FK506 (tacrolimus, Cat No. F4679) were purchased from SigmaAldrich (Bornem, Belgium). FTI-277 was a kind gift from Janssen Pharmaceutica (Beerse, Belgium). $1 \mathrm{mg} / \mathrm{ml}$ stock solutions of PI $(40 \times)$ and DAPI $(10,000 \times)$ were made in $\mathrm{H}_{2} \mathrm{O}$. Staurosporine and FTI-277 were dissolved in DMSO (Sigma-Aldrich, Cat No. 276855) in a stock solution of $1 \mathrm{mM}$. FK506 was dissolved in DMSO in a stock solution of $10 \mathrm{mM}(1000 \times)$. For Western blot the antihuman anti- $\alpha$-SYN antibody $15 G 7$ (1:100, Enzo Life Sciences, Cat No. ALX-804-258) was used and a mouse monoclonal anti- $\alpha$ tubulin antibody (1:50,000, Sigma, Cat No. T5168) was used as internal loading control. The rabbit polyclonal antibody against cleaved caspase-3 was purchased from Cell Signaling Technology (Danvers, MA, USA Cat No. 9661s), and used at 1:500 and 1:1000 for immunocytochemistry (ICC) and western blotting, respectively. The cytotoxicity detection kit was purchased from Roche (Cat No. 11644793001 ) and the lactate dehydrogenase activity was determined according to the manufacturer's instructions.

\subsection{Generation of polyclonal stable overexpression cell lines using lentiviral vectors}

cDNA encoding $\alpha$-SYN was cloned into the pCHMWS-IRES-puro lentiviral (LV) transfer plasmid. LV vectors encoding $\alpha$-SYN under control of the cytomegalovirus (CMV) promoter were prepared in house as previously described using the triple transfection method with a transfer plasmid (Geraerts et al., 2005), an envelope plasmid encoding VSV-G and a packaging plasmid ( $p 8.91$ ). The LV constructs allowed co-expression of the puromycin resistance gene from the same transcript as the $\alpha$-SYN cDNA via an internal ribosome entry site (IRES). The LV titer was determined via measurement of p24 antigen content by an enzyme linked immunosorbent assay (HIV-1 p24 ELISA kit, XpressBio Europe Cat No. XB-1000). Prior to transduction, $1.5 \times 10^{5} \mathrm{SH}$-SY5Y cells were plated in a 24 -well plate and grown in DMEM-complete. The following day, vector was applied to the cells for 2 days, after which the vector-containing medium was replaced by DMEM-complete with $1 \mu \mathrm{g} / \mathrm{ml}$ puromycin (Invitrogen, Cat No. ANT-PR-1). Overexpression of $\alpha$-SYN was controlled via western blot.

\subsection{Western blotting}

Cells were plated in 6-well plates $\left(2 \times 10^{6}\right.$ cells/well). After 1 day, cells were washed with PBS (Lonza, Cat No. BE15-512D) and 
lysed in $200 \mu \mathrm{l}$ 1\% SDS solution (Sigma-Aldrich Cat No. L3771). The SDS cell extracts were boiled for $2 \mathrm{~min}$, followed by 6 passages through a $30 \mathrm{G}$ insulin syringe. After determination of protein content by a BCA assay (Perbio Science Cat No. 23225ZZ), cell extracts containing $20 \mu \mathrm{g}$ of total protein were separated on $4-12 \%$ sodium dodecyl sulfate-polyacrylamide gels (NUPAGE, Thermo Fisher Scientific Cat No. NP0323BOX) and electroblotted onto polyvinylidene difluoride membranes (Bio-Rad, Cat No. 162-0177). Membranes were blocked with $4 \%$ milk, and incubated with specific antibodies against $\alpha$-SYN, cleaved caspase-3 and/or $\alpha$-tubulin. Detection was performed using chemiluminescence $\left(\mathrm{ECL}^{+}\right.$-kit, Thermo Fisher Scientific, Cat No. 32132X3), a horseradish peroxidase (HRP)conjugated secondary antibody (Dako) and the LAS-4000 imaging system (Fujifilm, Dusseldorf, Germany).

\subsection{Synucleinopathy cell culture model}

We used the cell culture model described by Ostrerova-Golts et al. to induce $\alpha$-SYN aggregation with a few modifications. Cells were plated in 96 -well plates $\left(1.5 \times 10^{4}\right.$ cells/well $)$. The next day, cells were treated for $72 \mathrm{~h}$ with $100 \mu \mathrm{M} \mathrm{H}_{2} \mathrm{O}_{2}$ (Sigma-Aldrich Cat No. $\mathrm{H} 1009$ ) and $5 \mathrm{mM}$ freshly prepared $\mathrm{FeCl}_{2}$ (Sigma-Aldrich Cat No. 372870) in DMEM-complete and filtered through a $0.22 \mu \mathrm{m}$ filter (Merck Millipore Cat No. SLGS033SS). Different concentrations of FTI-277 (a stock solution in DMSO was diluted 1000-fold) were added to this stress-inducing medium. The control condition received the same amount of DMSO. After three days, cells were washed with PBS and fixed with $4 \%$ formaldehyde (Sigma-Aldrich Cat No. F1635) for $15 \mathrm{~min}$. Cells were stored in PBS until analysis.

\subsection{Immunocytochemistry}

First, cells were stained with $1 \times$ PI in DMEM-complete for $30 \mathrm{~min}$. Afterwards, cells were fixed with $4 \%$ formaldehyde for 15 min, after 3 washes with PBS. After a blocking step with $2 \%$ BSA (Sigma-Aldrich Cat No. A2153) and 0.05\% Tween-20 (Sigma-Aldrich Cat No. P9416) in PBS for $1 \mathrm{~h}$, cells were incubated overnight with primary antibody against cleaved caspase- 3 in PBS plus $1 \%$ BSA. After washing twice with PBS for $15 \mathrm{~min}$, the cells were incubated for $1 \mathrm{~h}$ with a secondary Alexa Fluor 488-conjugated antibody (Life Technologies, Cat No. A11070). After a second washing step with PBS (2 times $15 \mathrm{~min}$ ), the cells were incubated with DAPI (1:10,000 in PBS) for $1 \mathrm{~h}$ and washed again with PBS twice and analyzed with the IN Cell Analyzer 2000 (GE Healthcare, Chalfont St. Giles, UK).

\subsection{Thioflavin S/DAPI staining of cells}

After oxidative stress induction and fixation, the cells were incubated with freshly prepared and filtered $(0.45 \mu \mathrm{m}$ filter, Merck Millipore Cat No. SLHA033SS) 0.1\% Thioflavin S (Thio S, SigmaAldrich Cat No. T1892) for $20 \mathrm{~min}$ and washed twice with $70 \%$ non-denatured ethanol (Sigma-Aldrich 02877) for $2 \mathrm{~min}$. Next, the cells in the wells were incubated with DAPI ( $1: 10,000$ in PBS). Plates were analysed using the IN Cell Analyzer 2000 within 1 day.

\subsection{High-content analysis of $\alpha$-SYN aggregation}

To quantify $\alpha$-SYN aggregation in our synucleinopathy cell culture model, we used the IN Cell Analyzer 2000 and IN Cell Investigator software (GE Healthcare) as described before (Gerard et al., 2010). For each cell line tested, six independent measurements were examined to obtain statistical information. Microscopic images of cell samples in a 96-well plate were generated in an automated manner with a $10 \times$ objective. After pre-defining the autofocusing step, three images were taken in three different channels (light source: xenon lamp) for each well: (1) DAPI staining (excitation filter at $360 \mathrm{~nm}$ and emission filter at $460 \mathrm{~nm}$, exposure time $250-500 \mathrm{~ms}$ ), (2) Thio $\mathrm{S}$ staining (excitation at $480 \mathrm{~nm}$, emission at $535 \mathrm{~nm}$, exposure time $1000-2000 \mathrm{~ms}$ ) and (3) bright field image (exposure time $50 \mathrm{~ms}$ ). This way, a total of 200-1000 cells were imaged and analyzed in each well. Images were further analyzed with a user-defined multi-target analysis protocol of the IN Cell Investigator software (IN Cell Analyzer Workstation). Information of four different parameters was extracted based on the respective channels used: (1) nucleus identification (wavelength 1), (2) cytoplasm identification (wavelength 2), and (3) inclusions in the cytoplasm (wavelength 2). Before analysis, segmentation parameters were pre-set and optimized, when necessary, to ensure correct detection of all image features. Overall, nuclei were detected via the DAPI staining (wavelength 1 ) with a top-hat mask. The minimal area and sensitivity for detection were, respectively, set at $20 \mu \mathrm{m}^{2}$ and 60-80. The cytoplasm was detected via the background Thio S staining (wavelength 2) with a multiscale top-hat mask. The characteristic detection area and the detection sensitivity were, respectively, set at $20 \mu \mathrm{m}^{2}$ and $60-80$. $\alpha$-SYN inclusions were detected in the cytoplasm based on increased fluorescence of the Thio $S$ staining compared with the background intensity. Again, a multiscale top-hat mask was applied. Upper and lower limit for granule size (10 scales) were, respectively, $1 \mu \mathrm{m}$ and $10 \mu \mathrm{m}$, while detection sensitivity was set to 60-80. Advanced sensitivity setting was 1.2-2.4. Data files were exported in MS Excel (Redmont, CA, US) and contained information about $\alpha$-SYN inclusion count, mean/total area and intensity. As further mentioned and as indicated in Section 3, the HCA of $\alpha$-SYN aggregation could be expanded with cell death parameters (see below).

\subsection{Manual counting of $\alpha$-SYN aggregation}

Intracellular fibrillar $\alpha$-SYN aggregates were detected after Thio $\mathrm{S}$ staining with a 488-argon ion laser. For each condition, at least eight independent samples (glass plates) were assayed ( $8 \leq n \leq 16$ for all experiments). Three confocal images were acquired of each sample with an inverted confocal fluorescence microscope (LSM 510 Meta; Carl Zeiss) after staining and 100 cells were determined to be aggregate positive or negative. The conditions of the experiment were blinded to the investigator scoring the cells.

\subsection{High-content analysis of cell death}

To quantify cell death in our synucleinopathy cell culture model, we used the IN Cell Analyzer 2000 and the IN Cell Investigator software, comparable to the analysis of $\alpha$-SYN aggregation. For each condition tested, at least 6 independent measurements were examined to obtain statistical significance. Again, microscopy images of cell samples in a 96-well plate were generated in an automated manner using the $10 \times$ objective. After pre-defining the autofocusing step, three images were acquired in four different channels (xenon lamp) for each well: (1) DAPI staining (excitation filter at $360 \mathrm{~nm}$ and emission filter at $460 \mathrm{~nm}$, exposure time $500 \mathrm{~ms}$ ), (2) immunocytochemical staining for cleaved caspase 3 (excitation at $480 \mathrm{~nm}$, emission at $535 \mathrm{~nm}$, exposure time $1500 \mathrm{~ms}$ ), (3)PI staining (excitation at $535 \mathrm{~nm}$, emission at $620 \mathrm{~nm}$, exposure time $500 \mathrm{~ms}$ ) and (4) bright field image (exposure time $50 \mathrm{~ms}$ ). This way, a total of 250-1000 cells were imaged and analyzed in each well. Images were further analyzed with a user-defined multi-target analysis protocol of the IN Cell Investigator software (IN Cell Analyzer Workstation). Information of five different parameters was extracted based on the respective channels used: (1) nucleus identification (wavelength 1), (2) cytoplasm identification (wavelength 2), (3) inclusions in the cytoplasm (wavelength 2), (4) inclusions in the 
nuclei and (5) PI staining (wavelength 3). Before analysis, segmentation parameters were pre-set and optimized, when necessary, to ensure correct detection of all image features. Nuclei were detected as described for the analysis of $\alpha$-SYN aggregation. The cytoplasm was detected via the background immunocytochemical staining for cleaved caspase 3 (wavelength 2) with a multiscale top-hat mask. The characteristic detection area and the detection sensitivity were, respectively, set at $20 \mu \mathrm{m}^{2}$ and 60-80. Activated caspase 3 was detected in the cytoplasm based on increased fluorescence of the immunocytochemical staining compared with the background intensity. Again, a multiscale top-hat mask was applied. Upper and lower limit for granule size ( 10 scales) were, respectively, $1 \mu \mathrm{m}$ and $10 \mu \mathrm{m}$, while detection sensitivity was set to 60. Possible apoptotic inclusions in the nucleus were detected via the DAPI staining (wavelength 1) with a multiscale top-hat mask. Upper and lower limit for granule size ( 7 scales) were, respectively, $1 \mu \mathrm{m}$ and $20 \mu \mathrm{m}$, while detection sensitivity was set to 50-60. Advanced sensitivity parameter was set to 5-9. PI staining (reference 1, wavelength 3 ) was detected in the nuclei. Data files were exported in MS Excel format and contained information about nucleus area, apoptotic and activated caspase 3 inclusion count, mean/total area and intensity. Cells were counted positive for PI when fluorescence intensity exceeded a threshold value, which was fixed after visual scoring of the cells.

\subsection{High-content data analysis and statistical analysis}

All information from the high-content analysis was exported to MS Excel as mentioned in Section 2.10. Per cell, the following parameters were further evaluated for both $\alpha$-SYN aggregation (cytoplasmic inclusions) and late apoptosis (nuclear inclusions): (i) presence, (ii) count (if present), (iii) intensity, (iv) mean area, and (v) total area of the inclusions. To analyze these data, a macro (visual basic) was written, which first divided the cells according to the well in which they were imaged (A1-H12 of a 96-well plate). Next, the parameters, which had to be analyzed were chosen. If the presence of inclusions (cytoplasmic or nuclear) was evaluated, this was determined to be true if the count of inclusions was equal to or larger than 1 . This resulted in a fraction of inclusion-positive cells per well. In the proportion of cells containing inclusions, the 25, 50 and 75 percentiles of the count, intensity and area of inclusions was determined per well.

For more detailed studies, additional parameters were evaluated: nuclear size and/or mean intensity of the Thio S, DAPI, activated caspase 3 or PI staining. These evaluations were fit in the macro as described above with some adaptations. To determine the mean Thio $S$ and DAPI intensity, the mean (cytoplasmic or nuclear) intensity of the respective dyes was determined for all the cells, per analyzed well. To determine PI staining, a cut-off fluorescence intensity was determined by the researcher above which cells were clearly PI positive. Per well, the proportion of cells above the cutoff was determined. To determine activated caspase 3 staining, the same procedure as for the detection of $\alpha$-SYN aggregate (Thio S) positive cells was followed.

For all these parameters, the analysis resulted in an (average) value per well. All wells representing a condition were averaged and the SEM was determined. In order to perform a powerful statistical analysis, data from different experiments were taken into account. All statistical analyses were performed in GraphPad Prism 5.0 (San Diego, CA, USA). An ANOVA followed by Dunnet or Bonferroni post test determined the statistical difference between the conditions. In case of non-normality, the non-parametric equivalent (Kruskal-Wallis) was chosen, followed by Dunn's test. $p$-Value $<0.05$ is indicated by ${ }^{*}, p<0.01$ by ${ }^{* *}$ and $p<0.001$ by ${ }^{* * *}$.

\subsection{Three-day uniformity plate assay}

The variability of the HCA assay was evaluated with a plate uniformity study that was run over 3 days to assess uniformity and separation of signals. SH-SY5Y cells overexpressing $\alpha$-SYN were plated in a 96 -well plate $\left(1.5 \times 10^{4}\right.$ cells/well $)$. To achieve the minimum (Min), maximum (Max) and intermediate (Mid) signals, cells were treated without (Min, $0.1 \%$ DMSO) or with oxidative stress ( $5 \mathrm{mM} \mathrm{FeCl}_{2}, 100 \mu \mathrm{M} \mathrm{H}_{2} \mathrm{O}_{2}$ and $0.1 \%$ DMSO) with (Mid) or without (Max) $10 \mu$ M FK506 the following day. After $72 \mathrm{~h}$, cells were fixed, stained with Thio S and analyzed. Next, the following statistical parameters were calculated for each plate:

- mean (AVG), standard deviation (SD), and coefficient of variation (CV) of the mean for each signal (Max, Min and Mid). The acceptance criteria are that the CV's of each signal be less than or equal to $20 \%$.

- for each of the "Mid"-signal wells, a percent activity for FK506 and SD were calculated: \%Activity $=\left(\right.$ well $\left._{\text {mid }}-\mathrm{AVG}_{\min }\right) /\left(\mathrm{AVG}_{\min }-\mathrm{AVG}_{\max }\right) \times 100$

The acceptance criterion is SDmid $\leq 20$ on all plates.

Signal Window (SW) and Z' factor $\left(Z^{\prime}\right)$ for each plate were calculated as described below. The acceptance criterion was $S W \geq 2$ and $\mathrm{Z}^{\prime} \geq 0.4$ on all plates.

The formula for the signal window is:

$$
\mathrm{SW}=\frac{\left(\mathrm{AVG}_{\max }-3 \mathrm{SD}_{\max } / \sqrt{ } n\right)-\left(\mathrm{AVG}_{\min }+3 \mathrm{SD}_{\min } / \sqrt{ } n\right)}{\mathrm{SD}_{\max } / \sqrt{ } n}
$$

where $n$ is the number of replicates of the test substance that is used for the assay.

$\mathrm{Z}^{\prime}$ factor formula is:

$Z^{\prime}=\frac{\left(A V G_{\max }-3 \mathrm{SD}_{\max } / \sqrt{ } n\right)-\left(A V G_{\min }+3 \mathrm{SD}_{\min } / \sqrt{ } n\right)}{A V G_{\max }-A V G_{\min }}$

\section{Results}

\subsection{Optimization of a high-content assay for quantification of $\alpha$-SYN aggregates and apoptosis in cell culture}

We previously developed a cell culture model to induce $\alpha$-SYN aggregation and cell death, in which SH-SY5Y neuroblastoma cells overexpressing $\alpha$-SYN were exposed to oxidative stress conditions using $\mathrm{H}_{2} \mathrm{O}_{2}$ and $\mathrm{FeCl}_{2}$ (Fig. $1 \mathrm{~A}$ ). After 3 days of treatment, $\alpha$-SYN inclusions were visualized by Thio $S$ staining (Fig. 1B, arrows) and apoptotic cells were identified by the intensity of DAPI staining. Now we optimized a multiparametric high-content method to speed up the quantification of $\alpha$-SYN inclusions and cell death formation in our cell culture model. The assay is based on the automated generation of fluorescence microscopy images of cell samples in a multi-well plate format, followed by automated image analysis. Six independent samples are examined for each cell line and on average 500-1000 cells are analyzed in each well. The cells are identified via DAPI nuclear staining (Fig. 1C, upper panel). The cytoplasm is detected based on the background of Thio S staining and $\alpha$-SYN aggregates were determined based on the presence of high intensity spots in the cytoplasm of several cells after Thio S staining (Fig. 1C, middle panel, yellow marker). Apoptotic cells were quantified by identifying spots of higher intensity in the DAPI staining (Fig. 1C, upper panel, pink marker).

In order to further validate this assay, we decided to optimize several parameters that induce $\alpha$-SYN aggregation and cell death. Therefore, we plated SH-SY5Y cells overexpressing $\alpha$-SYN in 96well plates and we exposed them to increasing concentrations of 

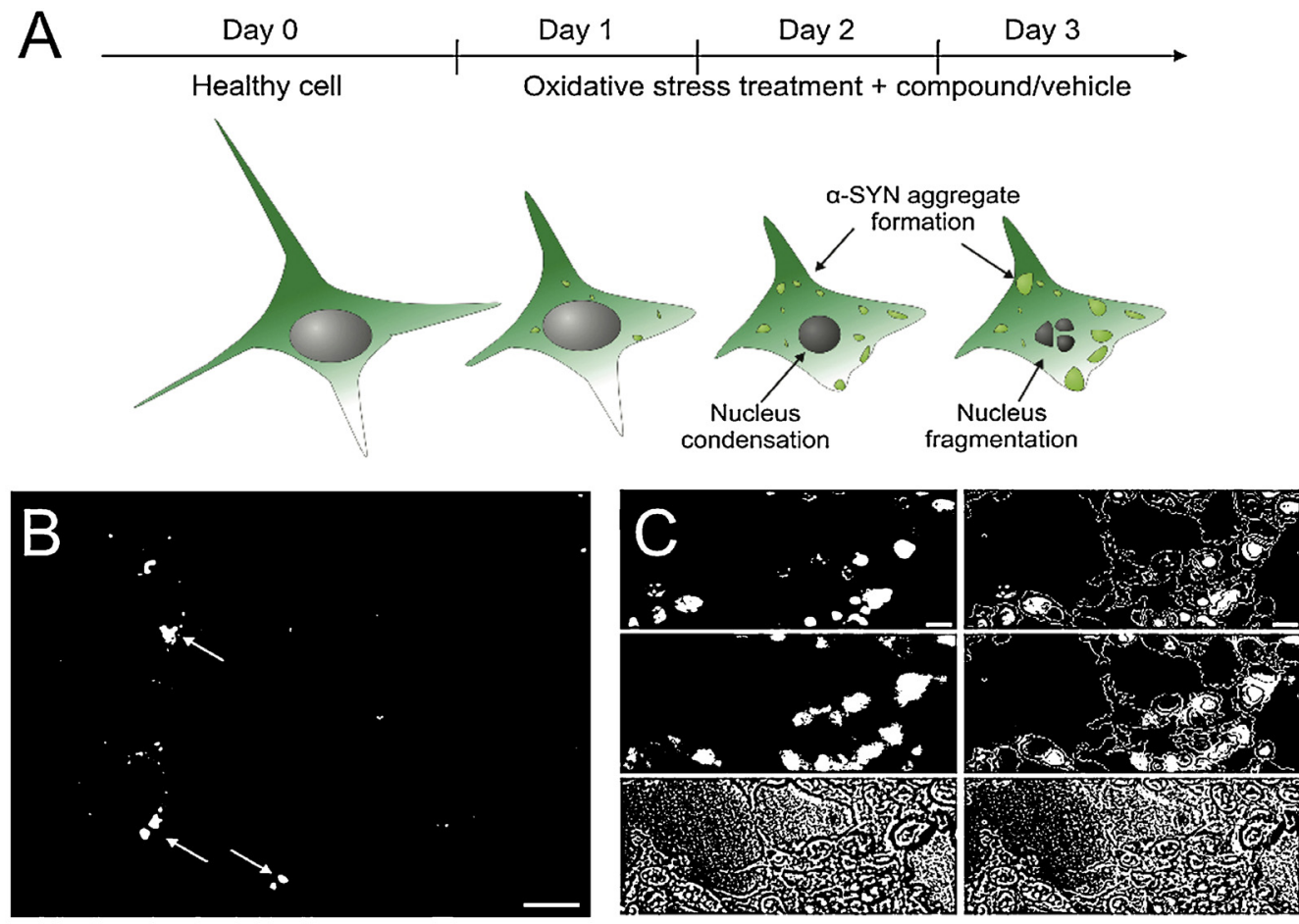

D

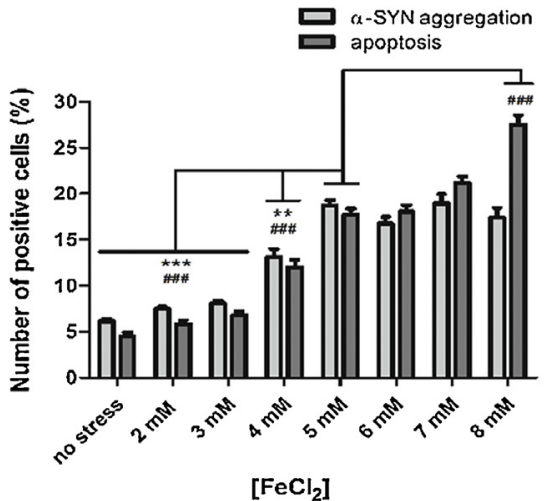

$\mathrm{F}$

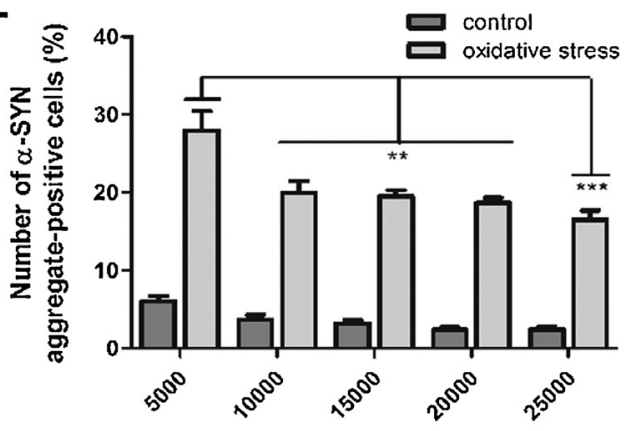

Number of cells
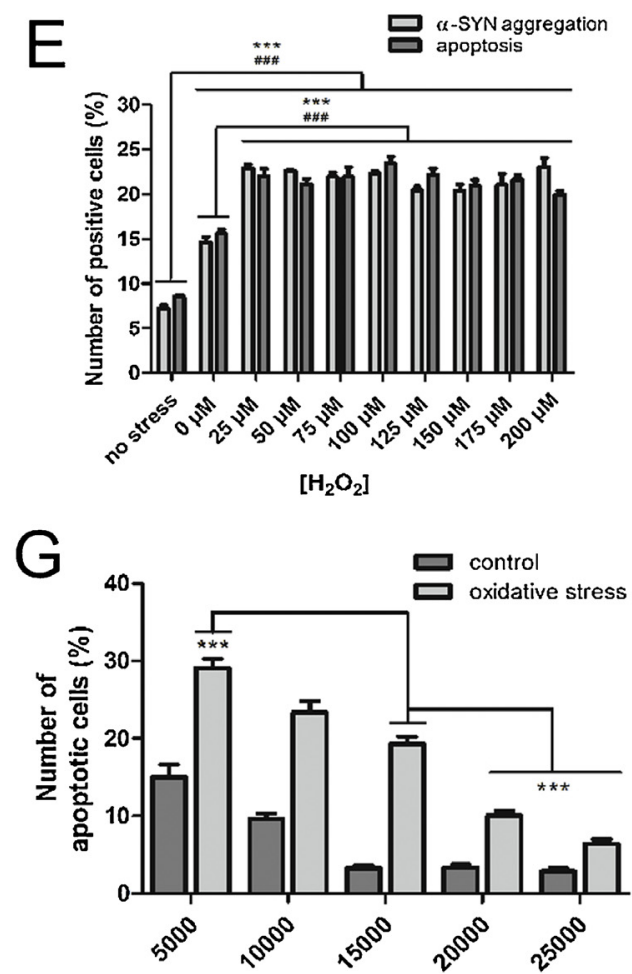

Number of cells

Fig. 1. Optimization of a high-content assay to measure $\alpha$-SYN aggregation and cell death in SH-SY5Y neuroblastoma cells. (A) Schematic representation of the synucleinopathy cell culture model. (B) Fluorescent microscopic image of Thio S-stained $\alpha$-SYN overexpressing SH-SY5Y cells that were subjected for three days to oxidative stress. Based on these images, the number of aggregate-positive and aggregate-negative cells was determined. Scale bar indicates $10 \mu \mathrm{m}$. (C) Fluorescent microscopic image of Thio S/DAPI-stained SH-SY5Y cells acquired with the IN cell analyzer. Upper panels: DAPI staining, middle panels: Thio S staining, lower panels: bright field image. Left panels: pictures without markers, right panels: identical pictures with markers. Blue marker: nucleus, green marker: cytoplasm, yellow marker: Thio S-positive $\alpha$-SYN aggregates, pink marker: apoptotic inclusions. Scale bars indicate $10 \mu \mathrm{m}$. High-content analysis of $\alpha$-SYN inclusion formation and apoptosis in SH-SY5Y cells exposed to increasing concentrations of $\mathrm{FeCl}_{2}$ (D) and $\mathrm{H}_{2} \mathrm{O}_{2}$ (E). Mean and SEM are shown for each condition $(n=3),{ }^{*} p$-values of $\alpha$-SYN aggregation; \# $p$-values of $\alpha$-SYN-induced apoptosis. High-content analysis of $\alpha$-SYN aggregates ((F) light grey bars) $\alpha$-SYN induced apoptosis $((\mathrm{G})$ light grey bars) with different cell seeding densities. As negative control, cells were not subjected to oxidative stress (dark grey bars). Mean and SEM are shown for each condition $(n=6)$. (For interpretation of the references to color in this figure legend, the reader is referred to the web version of this article.) 

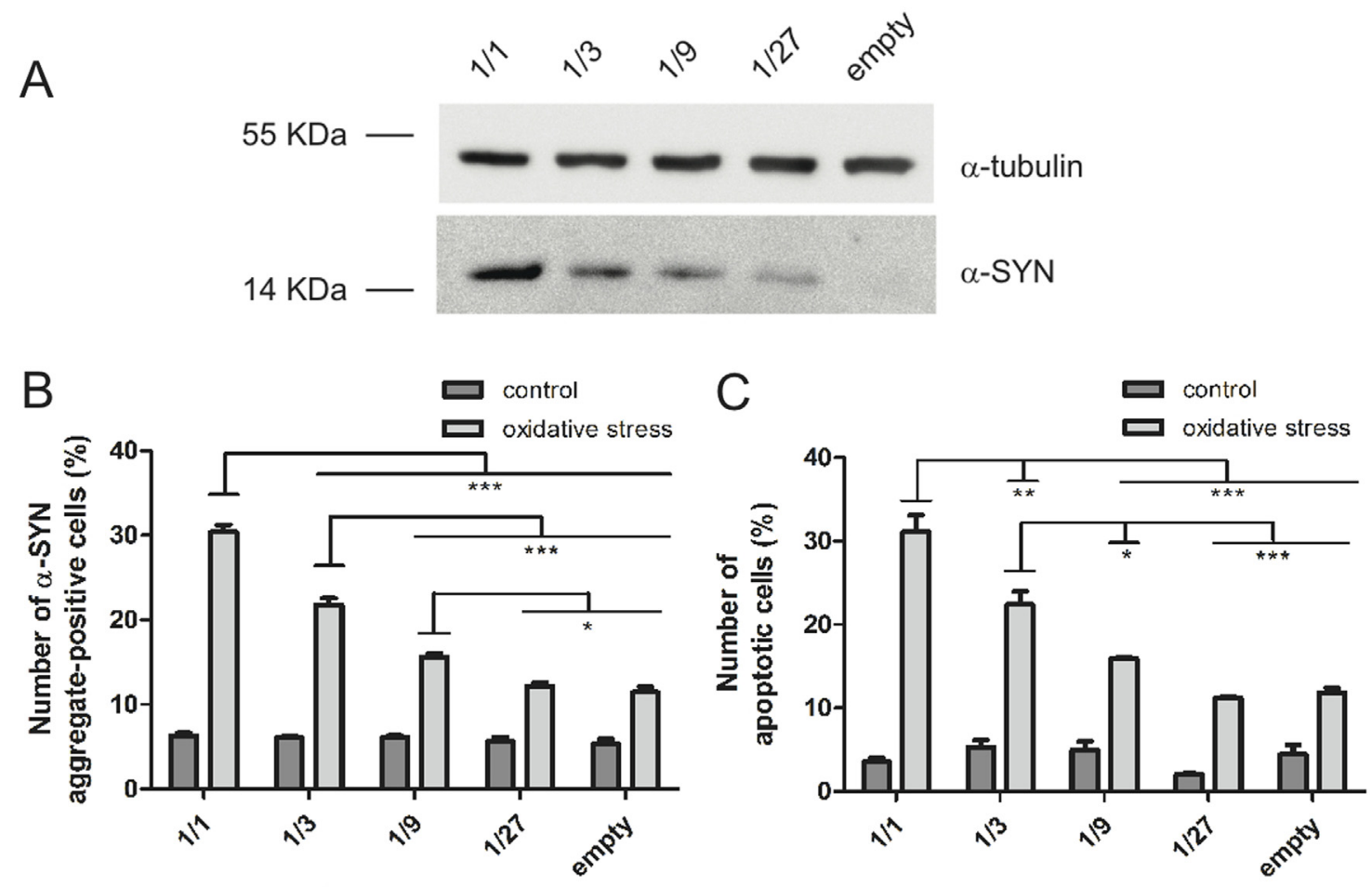

Dilution LV vector

Dilution LV vector

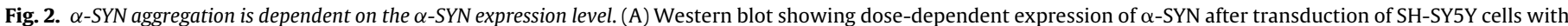

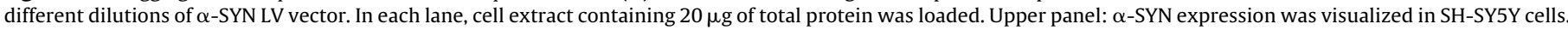

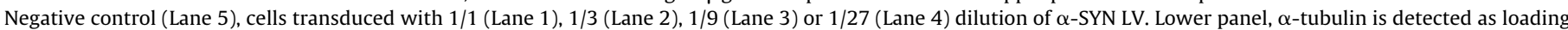

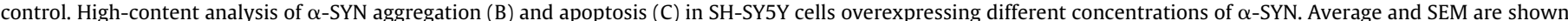
for each condition $(n=6)$.

$\mathrm{FeCl}_{2}$ and $\mathrm{H}_{2} \mathrm{O}_{2}$. Untreated cells were included as a negative control. Treatment with $\mathrm{FeCl}_{2}$ induced a dose-dependent formation of $\alpha$-SYN aggregates in the cells, in parallel with a dose-dependent cellular toxicity (Fig. 1D). Therefore, $5 \mathrm{mM}$ of $\mathrm{FeCl}_{2}$ was defined as the optimal concentration to promote $\alpha$-SYN aggregation and cell death without inducing an extreme toxicity. In addition $\mathrm{H}_{2} \mathrm{O}_{2}$ is required to increase $\alpha$-SYN inclusion formation and apoptosis in SH-SY5Y cells, but a concentration of $25 \mu \mathrm{M}$ was sufficient for the induction, without a clear dose-dependent effect up to $200 \mu \mathrm{M}$ (Fig. 1E). Hence, we used $100 \mu \mathrm{M}$ of $\mathrm{H}_{2} \mathrm{O}_{2}$ for further experiments to ensure a clear formation of $\alpha$-SYN inclusions and cell death.

Next, we evaluated the effect of cell density on $\alpha$-SYN aggregation and cell death. Different numbers of cells were plated in a 96-well plate to identify the optimal cell seeding density for the assay. No difference in the percentage of cells with $\alpha$-SYN aggregates was detected if $1 \times 10^{4}, 1.5 \times 10^{4}, 2 \times 10^{4}$ or $2.5 \times 10^{4}$ cells per well were plated (Fig. $1 \mathrm{~F}$ ). When $5 \times 10^{3}$ cells per well were seeded, an increase in $\alpha$-SYN aggregation was observed, but most of the cells were killed after the oxidative stress treatment. $\alpha$-SYN induced apoptosis decreased in parallel with the increment of cell seeding density (Fig. 1G). Therefore, we decided to Plate $1.5 \times 10^{4}$ cells per well for all further experiments, to get a proper induction of $\alpha$-SYN aggregation and apoptosis and an appropriate confluence of cells 3 days after plating.

\subsection{Evaluation of the correlation between $\alpha$-SYN expression levels and aggregation in the high-content assay}

As stated in the introduction, increased expression of WT $\alpha$ SYN due to locus duplication (Chartier-Harlin et al., 2004; Ibanez et al., 2004) or triplication might enhance the risk of developing PD. Importantly, a major implication from these observations is that
$\alpha$-SYN levels are a notable determinant in the severity of the parkinsonian phenotype. To further validate our HCA method, we verified whether we could observe a similar effect in our synucleinopathy model. Therefore, we generated stable cell lines by transduction of SH-SY5Y cells with different dilutions of an $\alpha$-SYN encoding LV vector, starting from an initial vector titer of $5.24 \times 10^{7} \mathrm{pg} / \mathrm{mL}$. Western blot confirmed the dose-dependent overexpression of the $\alpha$-SYN protein (Fig. 2A). To address whether $\alpha$-SYN dosage influences the formation of $\alpha$-SYN inclusions and $\alpha$-SYN toxicity, we subjected the different $\alpha$-SYN overexpressing cell lines to oxidative stress for three days and quantified the $\alpha$-SYN inclusions using Thio $S$ staining (Fig. 2B) and apoptotic cells by DAPI staining (Fig. 2C). The percentage of aggregate-positive cells and apoptotic cells increased significantly with increasing $\alpha$-SYN expression levels, revealing a positive correlation between $\alpha$-SYN aggregation and cell death and the amount of $\alpha$-SYN protein.

\subsection{Expansion to a multi-parametric assay for apoptotic cell death}

As combining a cell-based $\alpha$-SYN aggregation assay with readouts for apoptosis might provide important insights into the role of aggregate formation in cell death processes, we expanded our automated test system with several markers of cell death. To optimize the measurement of these cell death parameters, we treated $\alpha$-SYN overexpressing SH-SY5Y cells for $17 \mathrm{~h}$ with various concentrations of staurosporine, a protein kinase inhibitor that has been shown before to induce apoptosis in different cell types. After staurosporine treatment, the cells were (1) stained with PI, a marker for loss of plasma membrane integrity, (2) fixed and stained immunocytochemically for cleaved caspase-3, an early marker of apoptosis and (3) stained with DAPI to quantify nucleus condensation and 


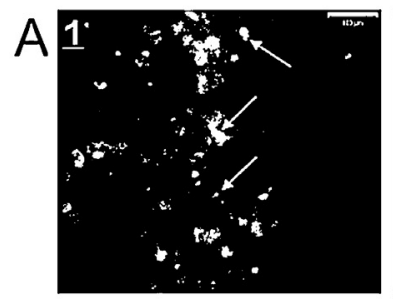

B

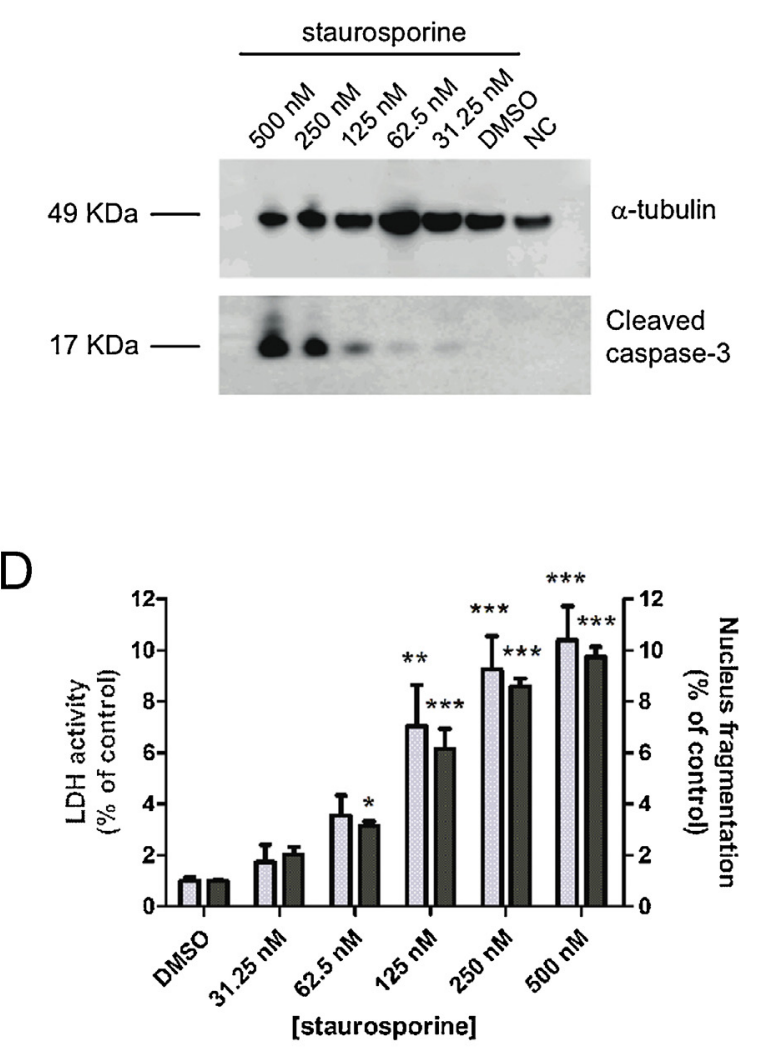

F

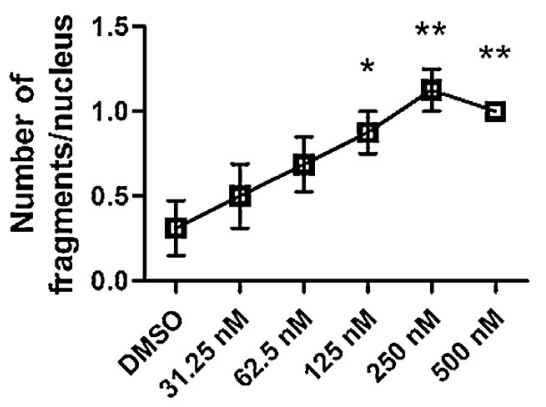

[staurosporine]
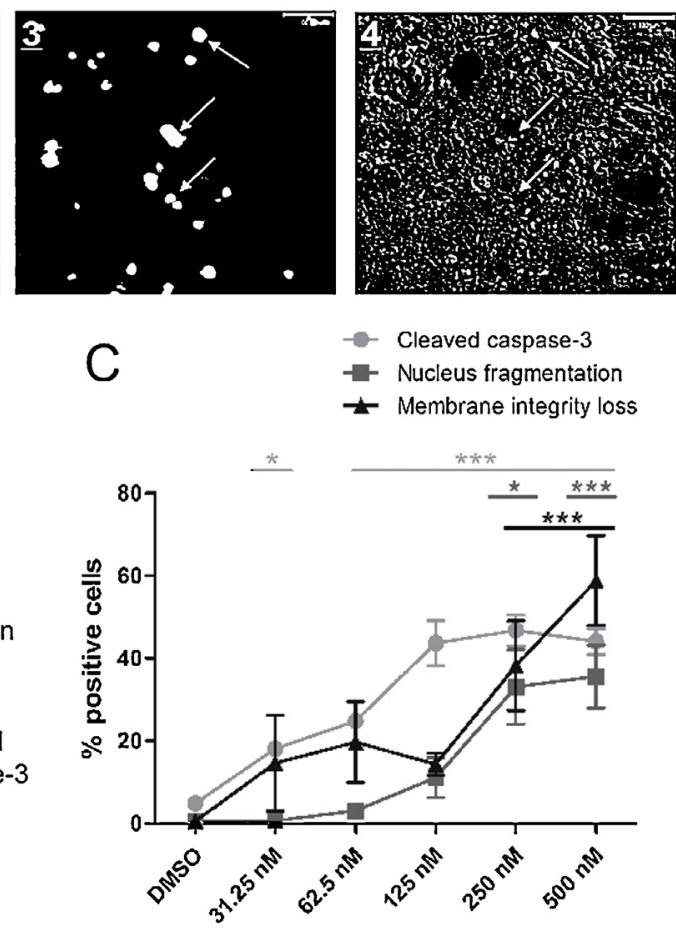

[staurosporine]

$E$

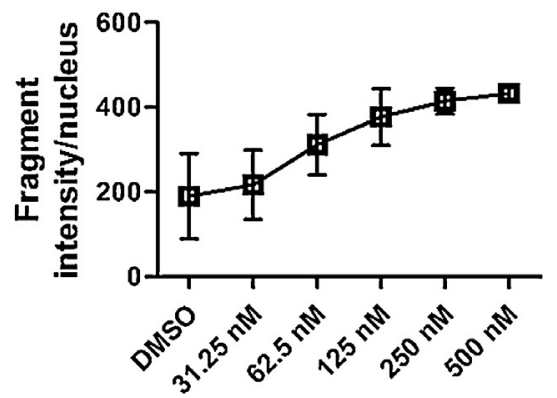

[staurosporine]

G

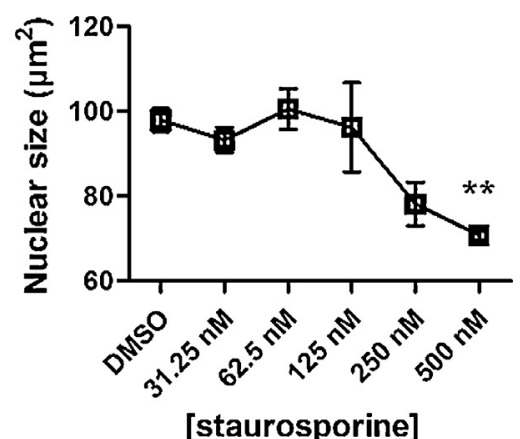

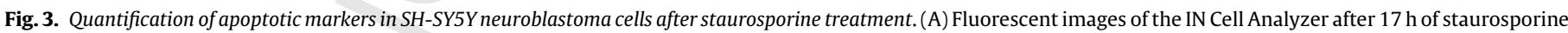

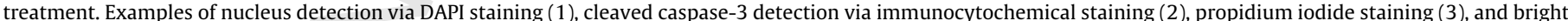

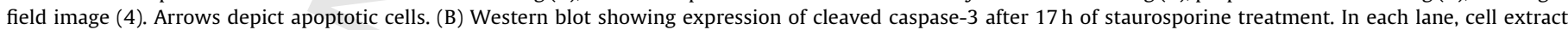

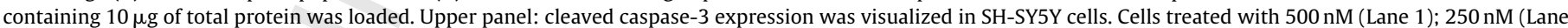

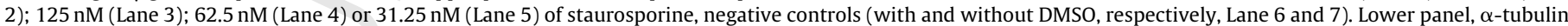

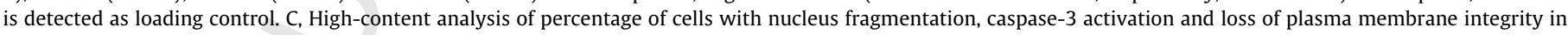

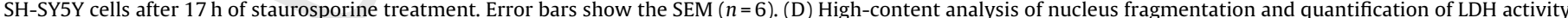

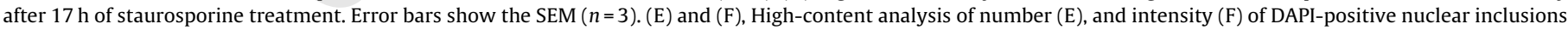

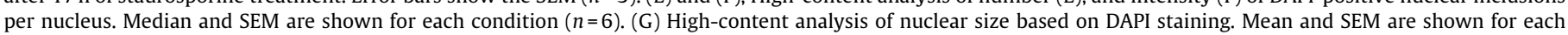
condition $(n=6)$. 
nucleus fragmentation, two late events in apoptosis. Then, according to predefined parameters, pictures were taken of each well (Fig. 3A 1-4). Based on the DAPI nuclear staining, the nuclear size and the presence of highly fluorescent nuclear fragments were used to quantify nucleus condensation and fragmentation, respectively, as described before (Gerard et al., 2010) (Fig. 3A 1). Simultaneously, cleaved caspase- 3 and PI staining were identified by the software. Caspase- 3 activation was detected in the cytoplasm based on spots with increased fluorescence compared to background fluorescence (Fig. 3A 2). PI staining was detected by its overall intensity in the nucleus (Fig. 3A 3). Before analysis, it was essential to verify the correct detection of these image features to limit the detection of false positives or negatives. Once the optimal parameters for segmenting were set, they were applied to all images in a standardized and objective manner. Our image acquisition and analysis protocols are described more in detail in Section 2.

Fig. 3C shows that staurosporine provoked apoptosis in a dosedependent way. All three parameters increased after treatment. For low staurosporine concentrations, cleaved caspase-3 seemed the most sensitive apoptosis parameter, while DAPI-based inclusions were only detected at higher concentrations, but exhibited a clear dose-dependency in the full staurosporine range; activated caspase- 3 reached a plateau at high staurosporine concentrations. Western blot confirmed the dose-dependent induction of cleaved caspase-3 (Fig. 3B). Next, to better estimate the accuracy of the cell death detection we compared our automated method to a cytotoxicity detection assay that measures lactate dehydrogenase (LDH) activity released from damaged cells. We exposed $\alpha$-SYN overexpressing SH-SY5Y cells to increasing concentrations of staurosporine and we quantified nucleus fragmentation and LDH activity after $17 \mathrm{~h}$. Fig. 3D shows that both LDH activity and nucleus fragmentation increase in a dose-dependent way after staurosporine treatment and no statistical difference was detected between the two methods.

When looking in further detail to the DAPI staining, more information was extracted beyond the percentage of apoptotic cells. In Fig. 3E and F, respectively, the number and intensity of nuclear areas with intense DAPI staining are provided. These also increase in a dose-dependent manner with staurosporine treatment. We further noticed that nuclear size (Fig. 3G), a marker for nuclear condensation, is inversely correlated with increasing staurosporine concentrations.

\subsection{Direct comparison of manual counting and the high-content assay for measuring the inhibition of $\alpha-S Y N$ aggregation by $a$ farnesyl transferase inhibitor}

Since farnesylation, a posttranslational modification, has been implied in $\alpha$-SYN neurotoxicity (Liu et al., 2009), we studied the effect of a farnesyl transferase inhibitor (FTI) 277 on $\alpha$-SYN aggregation and cell death, to further validate our cell culture assay. We incubated human neuroblastoma SH-SY5Y cells for three days with $\mathrm{FeCl}_{2}, \mathrm{H}_{2} \mathrm{O}_{2}$ and different concentrations of FTI-277 and we quantified the $\alpha$-SYN inclusions using Thio S staining and apoptotic cells by DAPI staining. Next, we compared the number of cells with Thio $\mathrm{S}$-positive aggregates, detected by blinded manual counting after confocal microscopy (Fig. 4A) or by HCA (Fig. 4B). With both manual detection of $\alpha$-SYN aggregation and automated HCA, we could clearly detect a concentration-dependent effect of FTI-277 on the percentage of cells containing $\alpha$-SYN fibrils. Although the absolute number of aggregate-positive cells differed between the two methods, the apparent $\mathrm{IC}_{50}$ was between 1 and $10 \mathrm{nM}$ for both manual and HCA. Moreover, HCA showed that the decrease in $\alpha-S Y N$ aggregation coincided with a beneficial effect on cell death.

\section{Table 1}

Three-day plate uniformity study for HCA synucleinopathy cell culture assay. Overview of the statistical analysis performed on three independent experiments run in three days to assess the variability and reproducibility of the HCA cell culture assay. The plate acceptance criteria are described in the first column of the table. In every plate the calculated statistical parameters are within the acceptable limits. CV: coefficient of variation of the mean; SD: standard deviation; Z': Z-prime factor; SW: signal window; SSMD: strictly standardized mean difference; AVG: mean; max: maximum signal; min: minimum signal; mid: intermediate signal.

\begin{tabular}{llll}
\hline & Plate 1 & Plate 2 & Plate 3 \\
\hline Intra-plate acceptance criteria & & & \\
$\mathrm{CV}_{\max } \leq 20 \%$ & $4 \%$ & $3 \%$ & $4 \%$ \\
$\mathrm{CV}_{\min } \leq 20 \%$ & $4 \%$ & $8 \%$ & $7 \%$ \\
$\quad$ Normalized $\mathrm{SD}_{\text {mid }} \leq 20$ & 11.98 & 12.98 & 9.13 \\
$\mathrm{Z}^{\prime} \geq 0.4$ & 0.81 & 0.83 & 0.73 \\
$\mathrm{SW} \geq 2$ & 16.48 & 23.15 & 12.52 \\
$\mathrm{SSMD} \geq 3$ & 4.35 & 5.31 & 3.39 \\
Inter-plate acceptance criteria & & & \\
Normalized $\mathrm{AVG}_{\text {mid }} \leq 2$-fold & 26.57 & 25.29 & 20.16 \\
$\quad$ difference between plates & & & \\
\hline
\end{tabular}

\subsection{Validation of the suitability of the high-content assay for drug screening}

We previously tested the effect of FK506, an immunophilin ligand that exhibits significant neuroregenerative and neuroprotective properties in models for neurodegeneration, in our cellular $\alpha$-SYN aggregation model. We showed that FK506 decreases the number of $\alpha$-SYN aggregates and protects against cell death (Deleersnijder et al., 2011; Gerard et al., 2010).

To further validate the assay for drug screening, we performed a 3-day plate uniformity study to evaluate the robustness and reproducibility of our HCA assay (Iversen et al., 2012). Uniformity assays were performed at the maximum (Max) and minimum (Min) signal to ensure that the signal window is adequate to detect active compounds during a screen. We ran three independent experiments over 3 days, using three different types of signals to determine the intra- and inter-plate variability of the assay. To obtain the Max and Min signals, $\alpha$-SYN overexpressing SH-SY5Y cells were exposed to high levels of oxidative stress or no oxidative stress, respectively. Cells were treated with FK506 in oxidative stress conditions to produce an intermediate signal (Mid), which estimates the signal variability at some point between the Max and Min signals. Next, we measured several statistical parameters in order to verify the reproducibility of our HCA assay. We calculated the signal window (SW), $\mathrm{Z}$ factors ( $\left.Z^{\prime}\right)$ and strictly standardized mean differences (SSMD) of each plate to evaluate the signal separation between Max and Min. Every plate displayed SW and SSMD higher than the recommended value ( 2 and 3, respectively) and a $Z^{\prime}$ higher than 0.7 , pointing at an excellent window for screening of inhibitors and stimulators of $\alpha$-SYN aggregation (Table 1 ). Moreover, the coefficient of variation (CV) of the Max and Min signal was always lower than 20\% and the standard deviation (SD) of the Mid signal percent activity values was lower than 20 in all plates. Finally, there was no significant variability among plates, since the difference between the normalized Mid signal was always lower than two-fold (Table 1), demonstrating the robust reproducibility of our assay.

\section{Discussion}

In recent years, an increasing number of studies has reported the use of high-content analysis (HCA) (Blackmore et al., 2010; Boyd et al., 2014; Radio, 2012) because HCA is an excellent method to bridge the gap between in vitro and in vivo disease model systems. in vitro systems allow screening of large numbers of molecules/conditions, but have low physiological relevance. In vivo models are much more physiologically relevant, but are labour- and cost-intensive and therefore often less suited for primary screening. 

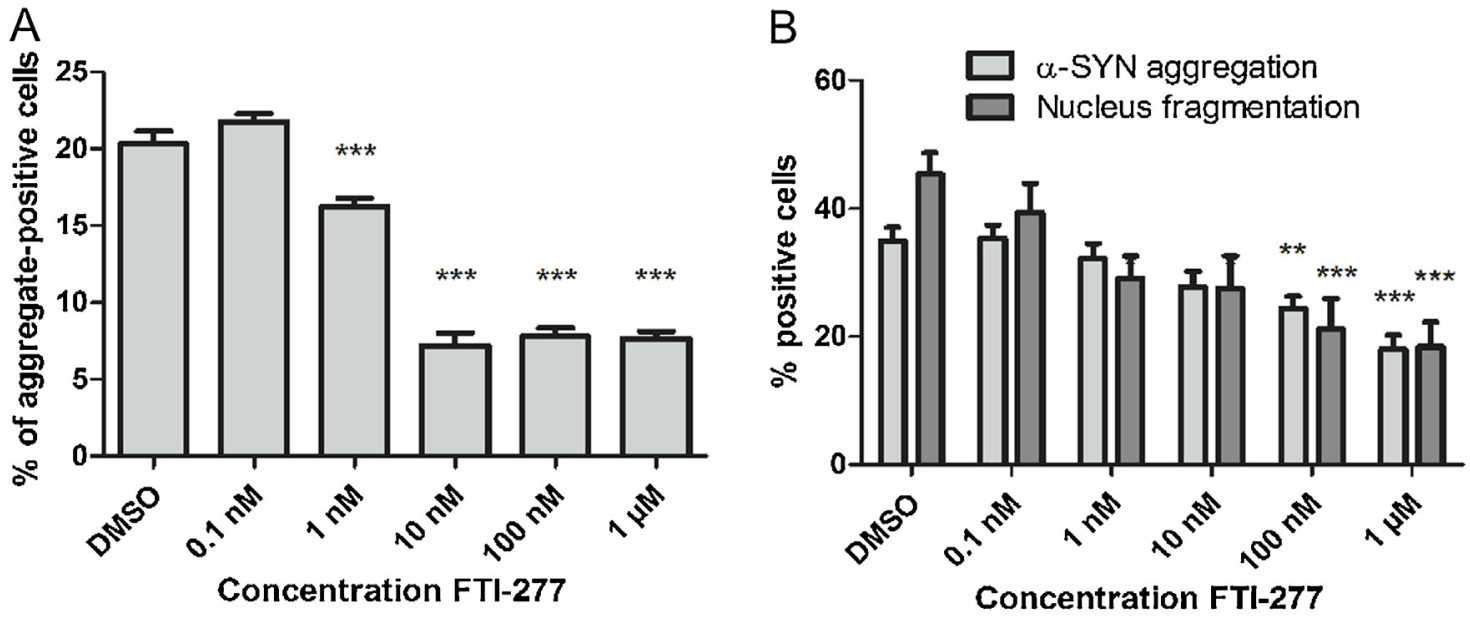

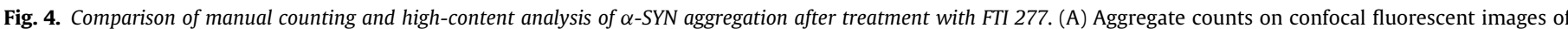

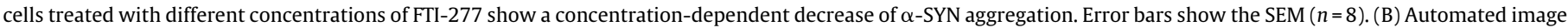

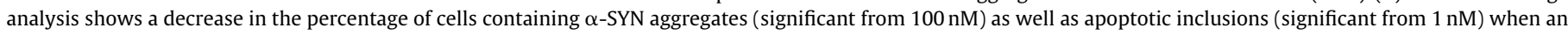
increasing concentration of FTI-277 is applied to the cells. Error bars show the SEM $(n=8)$.

Only a few reports have been made on the use of HCA in Parkinson's disease (PD) research in order to analyze $\alpha$-SYN content and $\alpha$-SYN cell-to-cell transfer or to screen for regulators of parkin translocation and inhibitors of rotenone toxicity (Bidinosti et al., 2012; Fitzgerald et al., 2003; Hansen et al., 2011; Hasson et al., 2013; Reyes et al., 2014) Previously, we described a neuronal cell-based assay that measures $\alpha$-SYN aggregation together with apoptotic cell death and we used this assay to investigate the role of FK506 binding proteins (FKBPs) on $\alpha$-SYN aggregation and neurodegeneration (Deleersnijder et al., 2013, 2011; Gerard et al., 2010). Here, we describe the optimization and validation of a HCA, which can be used for the identification of potential inhibitors of $\alpha$-SYN aggregation.

The first step in the optimization process was the establishment of the most efficient oxidative stress conditions and cell seeding density for 96 -well plates, to induce $\alpha$-SYN aggregation in human neuroblastoma cells overexpressing $\alpha-S Y N$ (Fig. 1). Next, we showed that the percentage of cells with $\alpha$-SYN inclusions after oxidative stress treatment depends on the expression level of $\alpha$ SYN in the cells (Fig. 2). Since in PD patients an increased expression of $\alpha$-SYN, due to gain of function mutations, duplications or triplications of the $\alpha$-SYN gene, is associated with a more severe pathology and elevated $\alpha$-SYN aggregation, this result confirmed the validity of our assay. Moreover, distinct statistical indices (SW, Z-factor and $\mathrm{CV}$ ) calculated in three experiment runs on different days clearly attested the reproducibility and robustness of our assay (Table 1). In order to verify that each experiment has worked properly, we always included untreated cells and cells exposed to oxidative stress treatment as control cells. We considered an experiment successful if we could observe at least a 2 -fold difference between these negative and positive control cells. Additionally, when testing the effect of compounds on $\alpha$-SYN aggregation or late apoptosis, we always include in each plate cells treated with FK506 as a positive control. We have shown previously that FK506 decreases the number of $\alpha$-SYN aggregates and apoptotic cells (Deleersnijder et al., 2011; Gerard et al., 2010). Moreover, since the cell density is crucial for an accurate performance of the assay, we verified that the cell growth would be comparable in the different experimental conditions and we included in the analysis wells with a total number of 200-1000 cells.

Taking advantage of the multiparametric nature of HCA assays, we next included read-outs for apoptosis in our assay, since this is an important end-point in neuroscience research (Kroemer et al., 2009). We expanded our automated test system to measure caspase-3 activation (via immunocytochemical staining), nuclear fragmentation (via DAPI staining) and loss of an intact plasma membrane (via PI staining) as markers of cell death. In a proofof-principle experiment, we demonstrated that staurosporine, a known inducer of apoptosis, dose-dependently decreased cell viability as shown by caspase- 3 activation, nuclear fragmentation and loss of plasma membrane integrity (Fig. 3). Although staurosporineinduced apoptosis was adequately reflected in the number of cells positive for, respectively, activated caspase-3, membrane integrity loss and nucleus fragmentation, the latter correlated best with $\alpha$ SYN aggregation. Combined with the fact that DAPI staining is less time consuming, we propose nuclear condensation as the preferred marker to follow $\alpha$-SYN toxicity in our HCA system. Moreover, we showed that the automated quantification of cell death in our assay correlates with the detection of LDH activity released by damaged cells after staurosporine treatment, demonstrating the fidelity of our method.

Next, for the validation of the high-content assay we also included an experimental comparison with standard methods. Therefore, we compared microscopic counting of $\alpha$-SYN aggregation with our high-content method, after treatment of SH-SY5Y cells with the commercially available farnesyl transferase inhibitor FTI-277 in our synucleinopathy cell culture model. Previous reports already associated farnesylation to PD (Liu et al., 2009). More specifically, it was shown that UCH-L1, a protein linked to PD (Elbaz et al., 2003; Maraganore et al., 2004; Momose et al., 2002; Wintermeyer et al., 2000), Alzheimer's disease (Xue and Jia, 2006) and Huntington disease (Naze et al., 2002), migrates to the endoplasmic reticulum membrane after farnesylation. Furthermore, the amount of membrane-associated UCH-L1 correlates with intracellular $\alpha$-SYN levels and neurotoxicity. When UCH-L1 farnesylation is chemically inhibited with FTI-277, $\alpha$-SYN levels are reduced and neuronal cell viability is improved. The authors' hypothesis is that inhibition of UCH-L1 farnesylation may result in the activation of a non-proteasomal pathway for $\alpha$-SYN degradation, such as chaperone-mediated autophagy or macroautophagy. Here, both manual and HCA of $\alpha$-SYN aggregation demonstrated that FTI-277 treatment dose-dependently reduces the number $\alpha$-SYN aggregate-positive cells in SH-SY5Y cells (Fig. 4). However, the sensitivity to detect absolute numbers of $\alpha$-SYN aggregates was higher for HCA (e.g. 35\% versus $20 \%$ of $\alpha$-SYN aggregate-positive cells for control DMSO condition in high-content analysis and manual assessment, respectively). We believe this is likely due to an underestimation of the percentage of $\alpha$-SYN aggregate-positive 
cells by microscopic counting, where small or less intense aggregates might be overlooked. Moreover, for the manual analysis we used confocal images, therefore only aggregates in one optical plane were visualized inside the cell. Furthermore, the quantification of the $\alpha$-SYN aggregate-positive cells in these images greatly depends on the subjective estimation of the blinded observer. The HCA method overcomes these problems, since it counts $\alpha$-SYN aggregates throughout the whole cell and objectively detects these aggregates above a threshold of fluorescence intensity. Another advantage of the HCA method is that it allows simultaneous quantification of several parameters. For FTI-277, we also quantified DAPI-fluorescence intensity as a measure of cell death; a positive correlation between $\alpha$-SYN aggregation and apoptosis was detected (Fig. 4B). This is in agreement with the previous report describing that FTI-277 treatment protects against $\alpha$-SYN accumulation and toxicity (Liu et al., 2009).In conclusion, we propose that this HCA cellular assay will be widely applicable for PD research, not only for basic research on the mechanism of $\alpha$-SYN inclusion formation, but also to validate new compounds targeting $\alpha$-SYN aggregation. Over the last decade, the transition of in vitro hits to efficacious compounds in more complex disease models in neurodegeneration research suffered from many unexpected failures (Varma et al., 2008). The major challenge in producing a successful drug candidate for further preclinical development and ultimately clinical trials is, whether efficacy in an in vitro assay can be translated to a whole-animal disease model. Our HCA neuronal assay is positioned in the middle of this drug discovery process, as it can help to bridge the gap between simplified in vitro $\alpha$-SYN aggregation tests and the complex biological context of a PD animal model. Moreover, it is best suited for deciphering molecular mechanisms of pathological processes in a quantitative biology fashion. We believe that our HCA method can provide more predictive value for in vivo benefit and clinical potential, and additionally, is scalable to evaluate larger numbers of compounds than animal models. As such, it can be used as a secondary screen to rank hits from a high-throughput screen, before advancement into full preclinical development.

\section{${ }_{691}$ Acknowledgements}

We acknowledge the Center of Human Genetics-Molecular and Developmental Genetics of the KU Leuven for the use of the IN Cell Analyzer and Dieder Moechars from Janssen Pharmaceutics, Belgium for providing FTI-277. FM is doctoral fellow supported by a grant from KU Leuven, aggregation by a farnesyl transInstitute for the Promotion of Innovation by Science and Technology in Flanders (projects IWT/SBO 80020 Neuro-TARGET and 130065 MIRIAD), doctoral fellowship to AD and postdoctoral fellowship to MG), the Flemish Research Foundation FWO-Vlaanderen (projects G.0768.10 and G.0927.14), the Michael J Fox Foundation (target validation 2010), the European Commission (FP7 project MEFOPA HEALTH-2009-241791; FP7 project INMiND HEALTH-F22011-278850) and the KU Leuven (OT/08/052A and OT/14/120).

\section{References}

Aelvoet S-A, Ibrahimi A, Macchi F, Gijsbers R, Van den Haute C, Debyser Z, et al. Noninvasive bioluminescence imaging of $\alpha$-synuclein oligomerization in mouse brain using split firefly luciferase reporters. J Neurosci 2014;34:16518-32.

Appel-Cresswell S, Vilarino-Guell C, Encarnacion M, Sherman H, Yu I, Shah B, et al. Alpha-synuclein p.H50Q, a novel pathogenic mutation for Parkinson's disease. Mov Disord 2013.

Bidinosti M, Shimshek DR, Mollenhauer B, Marcellin D, Schweizer T, Lotz GP, et al. Novel one-step immunoassays to quantify $\alpha$-synuclein: applications for biomarker development and high-throughput screening. J Biol Chem 2012;287:33691-705. ferase DBOF/10/063. This work received financial support from the
Blackmore MG, Moore DL, Smith RP, Goldberg JL, Bixby JL, Lemmon VP. High content screening of cortical neurons identifies novel regulators of axon growth. Mol Cell Neurosci 2010;44:43-54.

Boyd JD, Lee P, Feiler MS, Zauur N, Liu M, Concannon J, et al. A high content screen identifies novel compounds that inhibit stress-induced TDP-43 cellular aggregation and associated cytotoxicity. J Biomol Screening 2014;19:44-56.

Chartier-Harlin MC, Kachergus J, Roumier C, Mouroux V, Douay X, Lincoln S, et al. Alpha-synuclein locus duplication as a cause of familial Parkinson's disease. Lancet 2004;364:1167-9.

Deleersnijder A, Gerard M, Debyser Z, Baekelandt V. The remarkable conformational plasticity of alpha-synuclein: blessing or curse. Trends Mol Med 2013;19:368-77.

Deleersnijder A, Van Rompuy AS, Desender L, Pottel H, Buee L, Debyser Z, et al. Comparative analysis of different peptidyl-prolyl isomerases reveals FK506-binding protein 12 as the most potent enhancer of alpha-synuclein aggregation. J Biol Chem 2011;286:26687-701.

Denner P, Schmalowsky J, Prechtl S. High-content analysis in preclinical drug discovery. Comb Chem High Throughput Screen 2008;11:216-30.

Dragunow M. High-content analysis in neuroscience. Nat Rev Neurosc 2008;9:779-88.

Dragunow M, Greenwood JM, Cameron RE, Narayan PJ, O'Carroll SJ, Pearson AG, et al. Valproic acid induces caspase 3-mediated apoptosis in microglial cells. Neuroscience 2006;140:1149-56.

Elbaz A, Levecque C, Clavel J, Vidal JS, Richard F, Correze JR, et al. S18Y polymorphism in the UCH-L1 gene and Parkinson's disease: evidence for an age-dependent relationship. Mov Disord 2003;18:130-7.

Eslamboli A, Romero-Ramos M, Burger C, Bjorklund T, Muzyczka N, Mandel RJ et al. Long-term consequences of human alpha-synuclein overexpression in the primate ventral midbrain. Brain 2007;130:799-815.

Feany MB, Bender WW. A Drosophila model of Parkinson's disease. Nature 2000;404:394-8.

Fennell M, Chan $\mathrm{H}$, Wood A. Multiparameter measurement of caspase 3 activation and apoptotic cell death in NT2 neuronal precursor cells using high-content analysis. J Biomol Screen 2006;11:296-302.

Fitzgerald JC, Gao GP, Reyes-Sandoval A, Pavlakis GN, Xiang ZQ, Wlazlo AP, et al A simian replication-defective adenoviral recombinant vaccine to HIV-1 gag. J Immunol 2003;170:1416-22.

Gasser T. Molecular pathogenesis of Parkinson disease: insights from genetic studies Expert Rev Mol Med 2009;11:e22.

Geraerts M, Michiels M, Baekelandt V, Debyser Z, Gijsbers R. Upscaling of lentiviral vector production by tangential flow filtration. J Gene Med 2005;7:1299-310.

Gerard M, Deleersnijder A, Daniels V, Schreurs S, Munck S, Reumers V, et al. Inhibition of FK506 binding proteins reduces alpha-synuclein aggregation and Parkinson's disease-like pathology. J Neurosci 2010;30:2454-63.

Grimsey NL, Narayan PJ, Dragunow M, Glass M. A novel high-throughput assay for the quantitative assessment of receptor trafficking. Clin Exp Pharmacol Physio 2008;35:1377-82.

Hansen C, Angot E, Bergstrom AL, Steiner JA, Pieri L, Paul G, et al. alpha-Synuclein propagates from mouse brain to grafted dopaminergic neurons and seeds aggregation in cultured human cells. J Clin Invest 2011;121:715-25.

Harper JD, Lansbury PT Jr. Models of amyloid seeding in Alzheimer's disease and scrapie: mechanistic truths and physiological consequences of the time-dependent solubility of amyloid proteins. Annu Rev Biochem 1997;66: 385-407.

Hasson SA, Kane LA, Yamano K, Huang C-H, Sliter DA, Buehler E, et al. High-content genome-wide RNAi screens identify regulators of parkin upstream of mitophagy. Nature 2013;504:291-5.

Ibanez P, Bonnet AM, Debarges B, Lohmann E, Tison F, Pollak P, et al. Causal relation between alpha-synuclein gene duplication and familial Parkinson's disease. Lancet 2004:364:1169-71.

Iversen PW, Beck B, Chen YF, et al. HTS assay validation. In: Sittampalam GS, Nelson $\mathrm{CN}$, et al., editors. Assay guidance manual. Eli Lilly \& Company and the National $\mathbf{Q} 10$ Center for Advancing Translational Sciences; 2012.

Kirik D, Annett LE, Burger C, Muzyczka N, Mandel RJ, Bjorklund A. Nigrostriatal alphasynucleinopathy induced by viral vector-mediated overexpression of human alpha-synuclein: a new primate model of Parkinson's disease. Proc Natl Acad Sci USA 2003;100:2884-9.

Kirik D, Rosenblad C, Burger C, Lundberg C, Johansen TE, Muzyczka N, et al. Parkinson-like neurodegeneration induced by targeted overexpression of alphasynuclein in the nigrostriatal system. J Neurosci 2002;22:2780-91.

Kroemer G, Galluzzi L, Vandenabeele P, Abrams J, Alnemri ES, Baehrecke EH, et al Classification of cell death: recommendations of the Nomenclature Committee on Cell Death 2009. Cell Death Differ 2009;16:3-11.

Kruger R, Kuhn W, Muller T, Woitalla D, Graeber M, Kosel S, et al. Ala30Pro mutation in the gene encoding alpha-synuclein in Parkinson's disease. Nat Genet 1998;18:106-8.

Lakso M, Vartiainen S, Moilanen AM, Sirvio J, Thomas JH, Nass R, et al. Dopaminergic neuronal loss and motor deficits in Caenorhabditis elegans overexpressing human alpha-synuclein. J Neurochem 2003;86:165-72.

Lauwers E, Debyser Z, Van Dorpe J, De Strooper B, Nuttin B, Baekelandt V. Neuropathology and neurodegeneration in rodent brain induced by lentiviral vector-mediated overexpression of alpha-synuclein. Brain Patho 2003;13:364-72.

Lesage S, Anheim M, Letournel F, Bousset L, Honore A, Rozas N, et al. , for the French Parkinson's Disease Genetics Study G. G51D alpha-synuclein mutation causes a novel parkinsonian-pyramidal syndrome. Ann Neurol 2013.

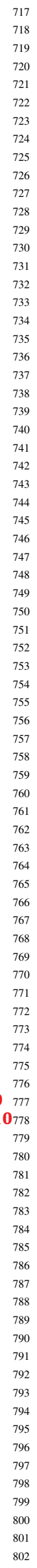


Liu Z, Meray RK, Grammatopoulos TN, Fredenburg RA, Cookson MR, Liu Y, et al. Membrane-associated farnesylated UCH-L1 promotes alpha-synuclein neurotoxicity and is a therapeutic target for Parkinson's disease. Proc Natl Acad Sci USA 2009; $106: 4635-40$.

Lubbe S, Morris H. Recent advances in Parkinson's disease genetics. J Neurol 2014;261:259-66.

Lundvig D, Lindersson E, Jensen PH. Pathogenic effects of alpha-synuclein aggregation. Brain Res Mol Brain Res 2005;134:3-17.

Maraganore DM, Lesnick TG, Elbaz A, Chartier-Harlin MC, Gasser T, Kruger R, et al. UCHL1 is a Parkinson's disease susceptibility gene. Ann Neurol 2004;55:512-21.

Mizuno Y, Hattori N, Kubo S, Sato S, Nishioka K, Hatano T, et al. Progress in the pathogenesis and genetics of Parkinson's disease. Philos. Trans. R. Soc. London, B: Biol. Sci 2008;363:2215-27.

Momose Y, Murata M, Kobayashi K, Tachikawa M, Nakabayashi Y, Kanazawa I, et al. Association studies of multiple candidate genes for Parkinson's disease using single nucleotide polymorphisms. Ann Neurol 2002;51:133-6.

Narayan PJ, Gibbons HM, Mee EW, Faull RL, Dragunow M. High throughput quantification of cells with complex morphology in mixed cultures. J Neurosci Methods 2007;164:339-49.

Naze P, Vuillaume I, Destee A, Pasquier F, Sablonniere B. Mutation analysis and association studies of the ubiquitin carboxy-terminal hydrolase L1 gene in Huntington's disease. Neurosci Lett 2002;328:1-4.

Olanow CW, Brundin P. Parkinson's disease and alpha synuclein is Parkinson's disease a prion-like disorder? Mov Disord 2013;28:31-40.

Oliveras-Salvá M, Macchi F, Coessens V, Deleersnijder A, Gérard M, Van der Perren A, et al. Alpha-synuclein-induced neurodegeneration is exacerbated in PINK1 knockout mice. Neurobiol Aging 2014;35:2625-36.

Oliveras-Salva M, Van der Perren A, Casadei N, Stroobants S, Nuber S, D'Hooge R et al. rAAV2/7 vector-mediated overexpression of alpha-synuclein in mouse substantia nigra induces protein aggregation and progressive dose-dependent neurodegeneration. Mol Neurodegener 2013;8:44.

Ostrerova-Golts N, Petrucelli L, Hardy J, Lee JM, Farer M, Wolozin B. The A53T alpha-synuclein mutation increases iron-dependent aggregation and toxicity. J Neurosci 2000;20:6048-54.

Polymeropoulos MH, Lavedan C, Leroy E, Ide SE, Dehejia A, Dutra A, et al. Mutation in the alpha-synuclein gene identified in families with Parkinson's disease. Science 1997;276:2045-7.

Radio N. Neurite outgrowth assessment using high content analysis methodology. In: Skaper SD, editor. Neurotrophic factors. Humana Press; 2012. p. 247-60.

Rausch 0 . Use of high-content analysis for compound screening and target selection. IDrugs 2005;8:573-7.
Reyes JF, Olsson TT, Lamberts JT, Devine MJ, Kunath T, Brundin P. A cell culture model for monitoring $\alpha$-synuclein cell-to-cell transfer. Neurobiol Dis 2014.

Schmandke A, Schmandke A, Pietro MA, Schwab ME. An open source based high content screening method for cell biology laboratories investigating cell spreading and adhesion. PLoS ONE 2013;8:e78212.

Scotter EL, Narayan P, Glass M, Dragunow M. High throughput quantification of mutant huntingtin aggregates. J Neurosci Methods 2008;171:174-9.

Singleton AB, Farrer M, Johnson J, Singleton A, Hague S, Kachergus J, et al. Alphasynuclein locus triplication causes Parkinson's disease. Science 2003;302:841.

Spillantini MG, Schmidt ML, Lee VM, Trojanowski JQ, Jakes R, Goedert M. Alphasynuclein in Lewy bodies. Nature 1997;388:839-40.

Teboul O, Feki A, Dubois A, Bozon B, Faure A, Hantraye P, et al. A standardized method to automatically segment amyloid plaques in Congo Red stained sections from Alzheimer transgenic mice. Conf Proc IEEE Eng Med Biol Soc 2007;2007: 5593-6.

Vallotton P, Lagerstrom R, Sun C, Buckley M, Wang D, De SM, et al. Automated analysis of neurite branching in cultured cortical neurons using HCA-Vision. Cytometry A 2007;71:889-95.

Van der Perren A, Toelen J, Casteels C, Macchi F, Van Rompuy A-S, Sarre S, et al. Longitudinal follow-up and characterization of a robust rat model for Parkinson's disease based on overexpression of alpha-synuclein with adeno-associated viral vectors. Neurobiol Aging 2014.

Van der Veken P, Fülöp V, Rea D, Gerard M, Van Elzen R, Joossens J, et al. P2-Substituted $\mathrm{N}$-acylprolylpyrrolidine inhibitors of prolyl oligopeptidase: biochemical evaluation, binding mode determination, and assessment in a cellular model of synucleinopathy. J Med Chem 2012;55:9856-67.

Varma H, Lo DC, Stockwell BR. High throughput screening for neurodegeneration and complex disease phenotypes. Comb Chem High Throughput Screen 2008;11:238-48.

Wang D, Lagerstrom R, Sun C, Bishof L, Valotton P, Götte M. HCA-vision. Automated neurite outgrowth analysis. J Biomol Screening 2010;15:1165-70.

Wintermeyer P, Kruger R, Kuhn W, Muller T, Woitalla D, Berg D, et al. Mutation analysis and association studies of the UCHL1 gene in German Parkinson's disease patients. NeuroReport 2000;11:2079-82.

Xue S, Jia J. Genetic association between ubiquitin carboxy-terminal hydrolase-L1 gene S18Y polymorphism and sporadic Alzheimer's disease in a Chinese Han population. Brain Res 2006;1087:28-32.

Zarranz JJ, Alegre J, Gomez-Esteban JC, Lezcano E, Ros R, Ampuero I, et al. The new mutation, E46K, of alpha-synuclein causes Parkinson and Lewy body dementia. Ann Neurol 2004;55:164-73. 